\title{
Effect of maltodextrin concentration and slurry temperature on pineapple powder using ultrasonic spray dryer
}

\author{
${ }^{2}$ Sukri, N., ${ }^{2}$ Hashib, S.A., ${ }^{2}$ Rahman, N.A., ${ }^{1 *}$ Hasfalina, C.M. and ${ }^{1}$ Abdulsalam, M. \\ ${ }^{1}$ Department of Biological and Agricultural Engineering, Faculty of Engineering, Universiti Putra \\ Malaysia, 43400 Serdang, Selangor, Malaysia. \\ ${ }^{2}$ Faculty of Chemical Engineering, Universiti Teknologi Mara (UiTM) Shah Alam, Selangor, Malaysia
}

\author{
Article history: \\ Received: 29 May 2018 \\ Received in revised form: 12 \\ September 2018 \\ Accepted: 25 September 2018 \\ Available Online: 6 \\ November 2018
}

Keywords:

Maltodextrin,

Moisture Content,

Pineapple,

Powder,

Ultrasonic Spray Dryer.

DOI:

https://doi.org/10.26656/fr.2017.2(6).116

\begin{abstract}
In order to prolong the shelf life of the pineapple, one of the methods that can be applied is spray drying. Ultrasonic Spray Drying (USD) relies on an electromechanical device that vibrates at a very high frequency. The main objective of this work is to study the effect of maltodextrin concentrations and pre-heat slurry temperature in order to improve pineapple powder yield and moisture content. The spray dryer model used was equipped with ultrasonic system and the samples were run at different preheat slurry temperatures of $30^{\circ}$ $\mathrm{C}, 40^{\circ} \mathrm{C}$, and $50^{\circ} \mathrm{C}$. Maltodextrin (MD) was used as a carrier agent at different concentrations ranging from $10 \%$ to $30 \% \mathrm{w} / \mathrm{w}$. The pineapple powder then was analyzed for its yield, moisture content and colour. It was found that at higher pre-heat slurry temperature and MD concentration, the drying yield of pineapple powder had also increased. The moisture content of pineapple powder decreased with an increase of preheat slurry temperatures and MD concentration. The pineapple was found to be spray dried best at $40^{\circ} \mathrm{C}$ pre-heat slurry temperature with $20 \% \mathrm{w} / \mathrm{w}$ MD concentration highest yield recorded was $127 \mathrm{~g}$. It was observed that the lightness colour of the powder is the highest at $40^{\circ} \mathrm{C}$ of slurry temperature and $20 \% \mathrm{w} / \mathrm{w}$ MD concentration. The pineapple slurry with high water to pineapple ratio resulted in low moisture content. In addition, the result shows that an increased amount of pineapple slurry and MD concentrations gives higher pineapple powder.
\end{abstract}

\section{Introduction}

Pineapples (Ananas comosus) is the third most important tropical fruit in world production after banana and citrus. The processing of pineapples has made the fruits well known throughout the temperate countries. Major pineapple products of international trade were canned slices, chunks, crush (solid pack), juice and fresh fruit. International trade is dominated by a few multinational companies that have developed the infrastructure to process and market pineapples. According to the nutrition data, pineapples are rich with nutrients, vitamins, and minerals including potassium, copper, manganese, calcium, magnesium, vitamin $\mathrm{C}$, beta-carotene, thiamine, B6, folate, as well as soluble and insoluble fiber, and bromelain (Soares et al., 2012). Its health and medicinal benefits include the ability to improve respiratory health, cure coughs and colds, improve digestion, strengthen bones, improve oral health, and increase circulation.

In order to prolong the shelf life of the pineapple, one of the methods that can be applied is spray drying. Spray drying by definition is a process where removal of moisture from solid material when rapid heat is applied (Luz et al., 2007). In a simpler understanding, spray drying is a method of producing a dry powder from a liquid or slurry by rapidly drying with a hot gas. This method is favorable for many thermally-sensitive substances such as foods and pharmaceuticals and the yield of this process has consistent particle size. During the spray drying process, air as heated drying medium; however, if the liquid is a combustible solvent such as ethanol or the product is oxygen-sensitive then nitrogen is used (Mujumdar, 2007). This technique involves evaporation from an atomized feed by mixing the spray and the drying medium. The complete process consists of a sequence of four steps namely atomization, mixing of spray (feed) and air, evaporation, and product separation.

Ultrasonic atomization relies on an electromechanical device that vibrates at a very high 
frequency. Two piezoelectric disks, tightened between a mechanical amplifying element and a support element, constitutes the electromechanical device of the ultrasonic atomizer. The fluid to be atomized initially passes over the surface of the vibrating piezoelectric disks, which sets ultrasonic vibrations within the liquid. The vibrations within the liquid cause molecules on the surface of the liquid to move about, disrupting the surface tension of the liquid. This creates areas on the surface of the liquid with reduced or no surface tension, which are very similar to holes in a sieve, and through which droplets of the liquid can escape (Anandharamakrishnan and Ishwarya, 2015). After bypassing the piezoelectric discs, the fluid passes through an amplifier, the tip of which is a resonant surface. On reaching the active resonant surface, a thin liquid film is formed. As the frequency of vibration approach the resonance frequency, a square wave pattern forms onto the liquid surface. Further increase in the amplitude of vibration causes the droplet formation and its detachment from the liquid film as can be seen in Figure 1.

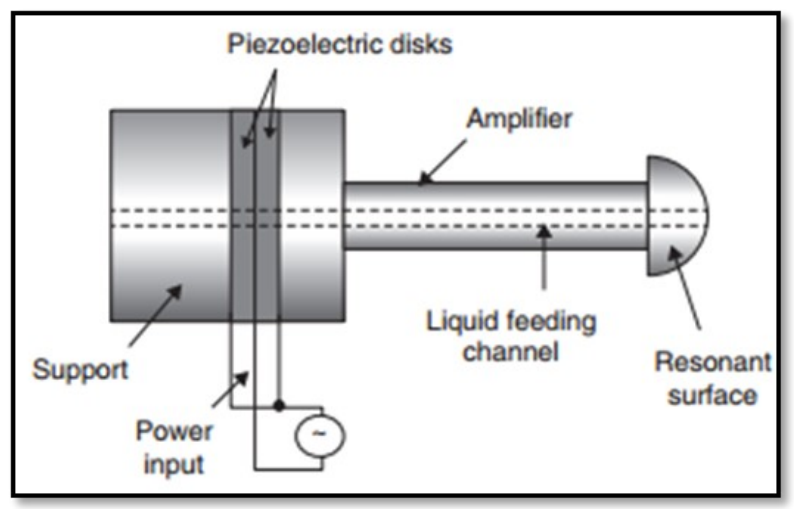

Figure 1. Ultrasonic atomizer (Dobre and Bolle, 2002)

In an ultrasonic atomizer, the feed droplet outlet is larger, with no moving parts, and this arrangement serves to prevent clogging, facilitates easy maintenance and operation (Anandharamakrishnan and Ishwarya, 2015). Because of the properties described above, ultrasonic atomizers have been effectively used for the drying of probiotic cells. However, ultrasonic atomization technology is effective only for low viscosity Newtonian fluids. Since reduced pressure acts as the driving force for moisture evaporation from the atomized droplets, use of the ultrasonic spray head demands large quantities of hot air. Nevertheless, the use of sterile and hot drying medium would render this method appropriate for aseptic manufacturing of spray dried particles (Anandharamakrishnan and Ishwarya, 2015).

Ultrasonic is an attractive procedure for drying heatsensitive foods. It is possible to dry more rapidly and at lower inlet air temperature than in the conventional driers by applying power ultrasound. Direct contact between samples and vibrating radiators significantly increases the drying rate. However, there are limited studies regarding the application of ultrasonic in the production of pineapple powders. The development of an efficient ultrasonic technology with better adaptability to conventional air driers need to be further study besides improving the physicochemical properties and increase the pineapple powder shelf life. Thus, the main objective of this experiment is to study the capability of an ultrasonic spray dryer in producing pineapple powder and the effect of maltodextrin concentration and the ratio of water to pineapple slurry towards powder yield, moisture content, sugar content and colour.

\section{Materials and methods}

\subsection{Pineapple juice preparation}

Fresh pineapple was obtained from Giant Shopping Centre in Section 7 Shah Alam. The pineapple was cut into three parts e.g. peel, core and flesh into cube size. After that, the pineapple flesh was crushed into juice by using Philips Laboratory Blender. The volume of distilled water used varied from 0 to $3 \mathrm{~L}$ into $500 \mathrm{~g}$ pineapple. Then, the juice was filtered by using sock sieve to remove pineapple fibrous formed. The extracted juice was stored in refrigerator at $4{ }^{\circ} \mathrm{C}$ overnight to allow the suspended particle to settle.

\subsection{Pineapple - maltodextrin slurry preparation}

The pineapple slurry was prepared by mixing $50 \mathrm{~g}$, $100 \mathrm{~g}$, and $150 \mathrm{~g}$ maltodextrin (MD) in order to obtain $10 \% \mathrm{w} / \mathrm{w}, 20 \% \mathrm{w} / \mathrm{w}$, and $30 \% \mathrm{w} / \mathrm{w}$ maltodextrin concentrations respectively into the pineapple slurry to form aqueous solution. The mixture was thoroughly stirred and heated at $30-50^{\circ} \mathrm{C}$ to ensure the maltodextrinpineapple slurry is smooth with no lumps.

\subsection{Ultrasonic Spray Dryer (USD)}

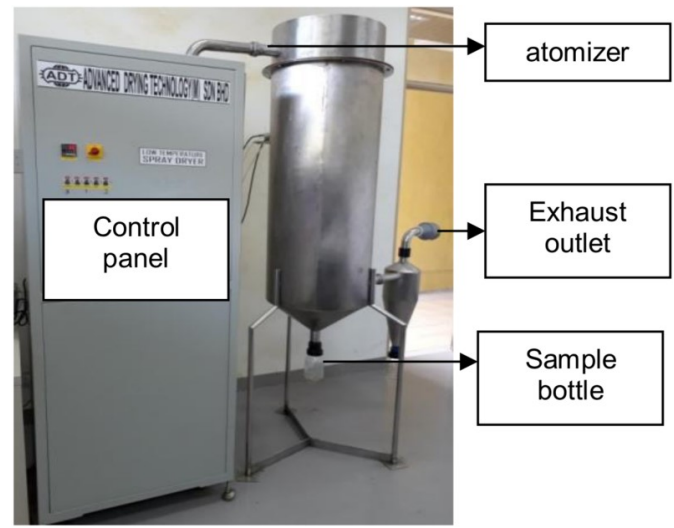

Figure 2. Locally installed ultrasonic spray dryer

The locally installed spray dryer by Advanced Drying Technology located at FRIM Kepong, has equipped with 40000 Hertz ultrasonic nozzle with a maximum feed capacity $3 \mathrm{~L} / \mathrm{h}$ as shown in Figure 2 . The 
USD was set with constant pump speed at approximately $1.742 \mathrm{~L} / \mathrm{h}$ and fixed inlet air temperature at $100^{\circ} \mathrm{C}$. Drying conditions for the USD process was set at three different maltodextrin concentrations: $50 \mathrm{~g}(10 \%), 100 \mathrm{~g}$ $(20 \%)$, and $150 \mathrm{~g}(30 \%)$ with three different pre-heated slurry temperatures at $30^{\circ} \mathrm{C}, 40^{\circ} \mathrm{C}$, and $50^{\circ} \mathrm{C}$.

\subsection{Moisture content analysis}

The moisture content of powder was determined using Sartorius moisture analyzer by adding one gram of powder in the moisture analyzer at $105^{\circ} \mathrm{C}$ for 10 mins. The results were recorded for all the experiment runs.

\subsection{Colour characteristics}

The spectrophotometer was switched on and left for about 15 mins. The desired wavelength was set for the system by fine-tuning the dial on the control panel. The transmittance was then set $0 \%$. After that, a "blank" cuvette containing distilled water was wiped. The cuvette was then inserted into the cell compartment inside the spectrophotometer. The transmittance value of the unit was set to $100 \%$ by rotating the dial. Then, the blank was removed. A total of $3 \mathrm{~mL}$ of the solution made from the spray-dried powder was inserted into the cuvette. Any bubbles inside the solution were tapped out and outer walls of the cuvette were wiped again prior to putting the cuvette into the cell compartment. The transmittance value and the absorbance value were read and recorded. Three Hunter parameters, namely L value (lightness of colour from 0 (black) to 100 (white)), a value (degree of redness $(0-60)$ / degree of greenness $(0-60))$ and $b$ value (yellowness (0-60) / blueness (0-60)) were measured and colour changes were calculated by using the formula below as calculated by Jamradloeluk et al. (2007) :

$$
\begin{aligned}
\Delta L & =L-L_{o} \\
\Delta a & =a-a_{o} \\
\Delta b & =b-b_{o}
\end{aligned}
$$

Where $L=$ lightness of dried sample; $a=$ redness/ greenness of dried sample; $b=$ yellowness/blueness of dried sample; $L_{o}, a_{o}$ and $b_{o}$ are initial values of the lightness, redness and yellowness of the sample prior to drying respectively.

\subsection{Yield of pineapple powder}

The yield of pineapple powder was determined based on collected powder in the powder bottle. The analysis of an optimum product yield was conducted using Design Expert 11 software where the relationships between drying yield, moisture content, colour and three independent variables which are volume of water used in pineapple slurry, maltodextrin concentrations, and preheated slurry temperature were studied.

\section{Results and discussion}

\subsection{Yield of pineapple powder}

Figure 3 (a) shows the effect of maltodextrin concentration and volume of water used at constant slurry temperature. As seen from this figure, the two factors have a significant combined effect on drying yield and increased in any of the factors reasonably increases the drying yield. The combined effect was observed to be greater at higher values of the two factors. However, the amounts of powder yield decrease as it exceeds $25 \mathrm{w} / \mathrm{w} \%$ maltodextrin concentration. This is because the optimum concentration of maltodextrin is about $25 \%$ on drying yield of pineapple powder. This supports the optimum conditions suggested by Suzihaque et al. (2015) and Hashib et al. (2015).

Figure 3 (b) shows the combined effect of preheat slurry temperature and volume of water used at constant maltodextrin concentration towards pineapple powder. It shows that the higher the preheat slurry temperature, the higher the drying yield due to the efficiency of heat and mass transfer process during the spray drying process greatly influence the drying yield. However, from the results obtained, the slurry temperature does show on that preheat slurry temperature in increasing the drying yield in ultrasonic spray drying process.

Figure 3 (b) shows the combined effect of preheat slurry temperature and maltodextrin concentration at a constant volume of water used in ultrasonic pineapple spray drying. The higher the maltodextrin concentration, the higher the drying yield. Similar findings have been observed in other studies conducted by Goula and Adamopoulos, (2010); Fazaeli et al. (2012) and Quek et al. (2007) where they reported that increment of maltodextrin concentration increases the yield of powders.

\subsection{Moisture content analysis}

Based on Figure 4, it was observed that an increase of maltodextrin concentration and the slurry temperature had reduced the moisture content of the powder. The increase of slurry temperature from $30^{\circ} \mathrm{C}$ to $50^{\circ} \mathrm{C}$, resulting in a significant decrease in the moisture content in pineapple powder from 7.78 to $7.17 \%$. This could be due to the increased rate of heat transfer into the particles at a higher temperature, and thus producing a greater driving force for moisture evaporation to speed up water removal (Caparino et al., 2012). The similar trend was observed in a study by (Acosta et al., 2015) on the effect of increasing level of maltodextrin from 10 to $15 \%(\mathrm{w} / \mathrm{v})$ in reducing moisture content from pineapple juice 


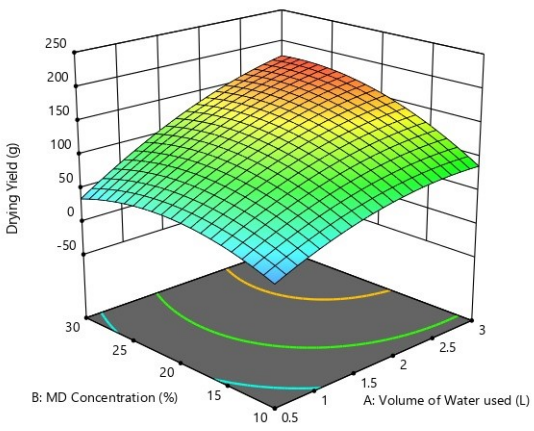

(a)

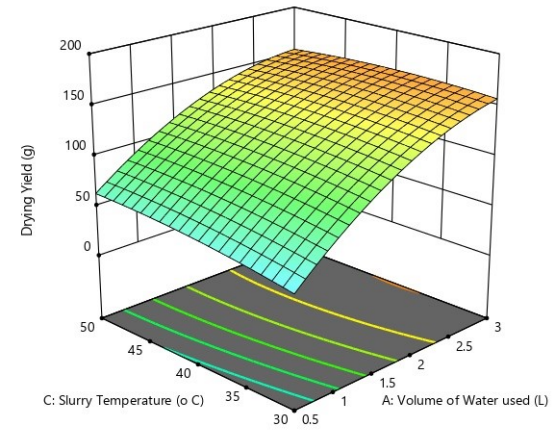

(b)

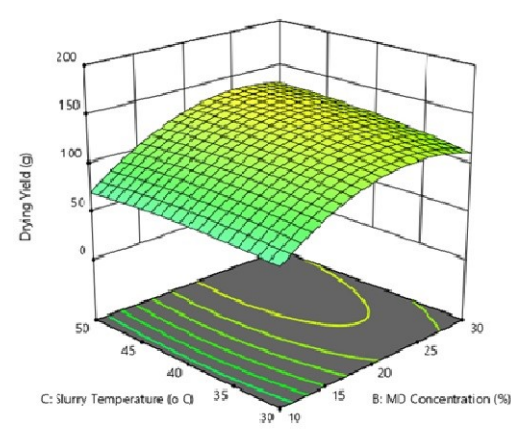

(c)

Figure 3. The combined effect of (a) maltodextrin concentration and volume of water used at constant slurry temperature, (b) pre heat slurry temperature and volume of water used at constant maltodextrin concentration and (c) pre heat slurry temperature and maltodextrin concentration at constant volume of water used

Table 1. The effect of maltodextrin concentration and slurry temperature on colour of pineapple powder.

\begin{tabular}{cccccc}
\hline \multirow{2}{*}{ Volume of water used (L) } & \multirow{2}{*}{ MD concentration (wt\%) } & \multirow{2}{*}{ Slurry temperature $\left({ }^{\circ} \mathrm{C}\right)$} & \multicolumn{3}{c}{ Colour } \\
\cline { 4 - 6 } & & 30 & $L^{*}$ & $a^{*}$ & $b^{*}$ \\
\hline 0.50 & 10 & 50 & 85.83 & -1.17 & 12.77 \\
0.50 & 10 & 30 & 96.15 & -1.04 & 15.94 \\
0.50 & 30 & 50 & 95.10 & -0.85 & 7.93 \\
0.50 & 30 & 40 & 97.87 & -1.22 & 5.98 \\
1.75 & 20 & 23.18 & 96.61 & -1.50 & 6.88 \\
1.75 & 20 & 56.82 & 93.02 & -1.76 & 9.77 \\
1.75 & 20 & 40 & 42.37 & 8.42 & 26.49 \\
1.75 & 3.18 & 40 & 90.96 & -2.70 & 13.04 \\
1.75 & 36.82 & 30 & 94.25 & -2.06 & 16.97 \\
3.00 & 10 & 50 & 91.92 & -0.83 & 16.66 \\
3.00 & 10 &
\end{tabular}

powder. Increased level of maltodextrin increased the affected by maltodextrin and temperature. The lightness level of feed solids and consequently reduced the level of of the powders was significantly affected by total moisture for evaporation (Candia-Muñoz et al., maltodextrin concentration when powders were 2015). The present findings were in agreement with the produced at slurry temperatures below $57^{\circ} \mathrm{C}$. The highest results obtained for spray dried tomato powder (Ramos value of $\mathrm{L}^{*}$ was obtained with $20 \%$ concentration of et al., 2016), orange juice powder (Santiago et al., 2016), maltodextrin at $40^{\circ} \mathrm{C}$ of preheat slurry temperature.

cactus pear juice powder (Rodriguez-Hernandez et al., 2005), black carrot powder (Dellacassa et al., 2017) and gac juice powder (Vladić et al., 2016).

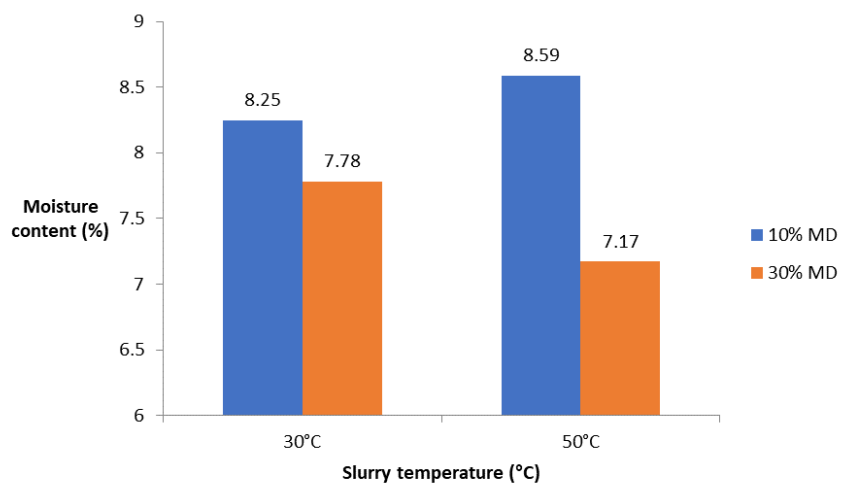

Figure 4. The effect of MD concentrations and slurry temperature on moisture content.

Table 1 shows the effect of different concentrations of maltodextrin and slurry temperatures on colour characteristics of spray dried powder. In general, the colour attributes of the powder were significantly

\section{Conclusion}

Pineapple powders were successfully prepared by ultrasonic spray drying, however at higher moisture content. The pineapple was found to be dried best at spray drying conditions of $40^{\circ} \mathrm{C}$ preheat slurry temperature with $20 \% \mathrm{w} / \mathrm{w}$ maltodextrin concentration as the highest yield of powder was produced is $185 \mathrm{~g}$. Besides, it was also found that the lightness colour of the powder is the highest at $40^{\circ} \mathrm{C}$ of slurry temperature and $20 \% \mathrm{w} / \mathrm{w}$ of maltodextrin concentration. This work concluded that the higher the maltodextrin concentrations, the higher the lightness and product yield produced. This is because, the maltodextrin can provide an additional attraction to the product by reducing the volatility and reactivity of the product.

\section{Acknowledgment}

The funding for this research was provided by 
Lestari Grant Scheme (600-IRMI/MYRA 5/3/LESTARI (0143/2016), Universiti Teknologi MARA (UiTM) Shah Alam and research collaboration with Advanced Drying Technology (M) Sdn Bhd from FRIM-MTDC.

\section{References}

Acosta, V., Bon, J., Riera, E. and Pinto, A. (2015). Ultrasonic drying processing chamber. Physics Procedia, 70, 854-857. https://doi.org/10.1016/ j.phpro.2015.08.175

Anandharamakrishnan, C. and Ishwarya, S.P. (2015). Spray Drying Techniques for Food Ingredient Encapsulation. $1^{\text {st }}$ ed. USA: Wiley Blackwell.

Candia-Muñoz, N., Ramirez-Bunster, M., VargasHernández, Y. and Gaete-Garretón, L. (2015). Ultrasonic spray drying vs high vacuum and microwaves technology for blueberries. Physics Procedia, 70, 867-871. https://doi.org/10.1016/ j.phpro.2015.08.178

Caparino, O.A., Tang, J., Nindo, C.I., Sablani, S.S., Powers, J.R. and Fellman, J.K. (2012). Effect of drying methods on the physical properties and microstructures of mango (Philippine "Carabao" var.) powder. Journal of Food Engineering, 111(1), 135-148.

https://doi.org/10.1016/

j.jfoodeng.2012.01.010

Dellacassa, E., Trenchs, O., Fariña, L., Debernardis, F., Perez, G., Boido, E. and Carrau, F. (2017). Pineapple (Ananas comosus L. Merr.) wine production in Angola: Characterisation of volatile aroma compounds and yeast native flora. International Journal of Food Microbiology, 241, 161-167. https://doi.org/10.1016/j.ijfoodmicro.2016.10.014

Fazaeli, M., Emam-Djomeh, Z., Kalbasi-Ashtari, A. and Omid, M. (2012). Effect of process conditions and carrier concentration for improving drying yield andother quality attributes of spray dried black mulberry (Morus nigra) juice. International Journal of Food Engineering, 8(1), 1-20.

Goula, A.M. and Adamopoulos, K.G. (2010). A new technique for spray drying orange juice concentrate. Innovative Food Science and Emerging Technologies, 11(2), 342-351. https:// doi.org/10.1016/j.ifset.2009.12.001

Hashib, S.A., Rahman, N.A., Suzihaque, M.U.H., Ibrahim, U.K. and Hanif, N.E. (2015). Effect of Slurry Concentration and Inlet Temperature Towards Glass Temperature of Spray Dried Pineapple Powder. Procedia - Social and Behvaioral Sciences, 195, 2660-2667. https://doi.org/10.1016/ j.sbspro.2015.06.472

Luz, P.P., Pires, A.M. and Serra, O.A. (2007). A Low-
Cost Ultrasonic Spray Dryer To Produce Spherical Microparticles From Polymeric Matrices. Quimica Nova, 30(7), 1744-1746. https://doi.org/10.1590/ S0100-40422007000700041

Mujumdar, A.S. (2007). Handbook of industrial drying. 3rd ed., p. 571-573 Boca Raton, Florida, USA: $\mathrm{CRC} /$ Taylor and Francis,

Quek, S.Y., Chok, N.K. and Swedlund, P. (2007). The physicochemical properties of spray-dried watermelon powders. Chemical Engineering and Processing, 46(5), 386-392. https://doi.org/10.1016/ j.cep.2006.06.020

Ramos, F.D.M., Oliveira, C.C.M.D., Soares, A.S.P. and Silveira Júnior, V. (2016). Assessment of differences between products obtained in conventional and vacuum spray dryer. Food Science and Technology, 36, 724-729. https://doi.org/10.1590/1678457X.09216

Santiago, M.C.P.D.A., Nogueira, R.I., Paim, D.R.S.F., Gouvêa, A.C.M.S., Godoy, R.L.D.O., Peixoto, F.M., Pacheco, S. and Freitas, S.P. (2016). Effects of encapsulating agents on anthocyanin retention in pomegranate powder obtained by the spray drying process. LWT - Food Science and Technology, 73, 551-556. https://doi.org/10.1016/j.lwt.2016.06.059

Soares, P.A.G., Vaz, A.F.M., Correia, M.T.S., Pessoa, A.Jr. and Carneiro-da-Cunha, M.G. (2012). Purification of bromelain from pineapple wastes by ethanol precipitation. Separation and Purification Technology, 98, 389-395. https://doi.org/10.1016/ j.seppur.2012.06.042

Suzihaque, M.U.H., Hashib, S.A. and Ibrahim, U.K. (2015). Effect of Inlet Temperature on Pineapple Powder and Banana Milk Powder. Procedia - Social and Behavioral Sciences, 195, 2829-2838. https:// doi.org/10.1016/j.sbspro.2015.06.401

Vladić, J., Ambrus, R., Szabó-Révész, P., Vasić, A., Cvejin, A., Pavlić, B. and Vidović, S. (2016). Recycling of filter tea industry by-products: Production of A. millefolium powder using spray drying technique. Industrial Crops and Products, 80, 197-206. https://doi.org/10.1016/ j.indcrop.2015.11.085 